\title{
Poiesis e imaginação na experiência estética: 0 momento da graça no jogo de computador
}

\author{
Dominic Arsenault \\ Doutor; Universidade de Montreal, Quebec, Canadá \\ dominic.arsenault@umontreal.ca
}

\author{
Maude Bonenfant \\ Doutora; Universidade do Quebec em Montreal, Quebec, Canadá \\ bonenfant.maude@uqam.ca \\ Tradução: Thiago Falcão \\ Universidade Federal do Maranhão, São Luís, MA, Brasil \\ thfalcao@gmail.com \\ Revisão de tradução: Breno Maciel \\ Universidade Federal do Rio Grande do Sul, Porto Alegre, RS, Brasil \\ brenomaciel@gmail.com
}

\section{Resumo}

Qual é a natureza da experiência de um jogador de videogames? Ter uma experiência de um jogo de computador é ter uma experiência funcional, adaptada à sua função como jogo de computador. Essa função é definida pela soma das propriedades que produzem o significado de uma experiência de jogo de computador, distinta das outras experiências da existência humana: o jogador atribui esse significado particular à sua experiência em vez de outro. As propriedades dessa experiência podem ser divididas entre suas muitas dimensões, como técnica (têkhné), ética (ethos), estética (aisthêtikos), etc., e são responsáveis pela riqueza e complexidade da experiência humana. Essas dimensões não podem ser visualizadas separadamente de seus efeitos combinados e funcionam como um todo inseparável que define o sentido da vida. No entanto, para as necessidades da nossa demonstração, vamos nos concentrar em um estudo da dimensão estética da experiência do jogador de games para mostrar como ele se desdobra, independente da diversidade dos jogos jogados, sejam eles Super Mario Bros. (Nintendo), Mount and Musket: Battalion (independente) ou Trauma (Krystian Majewski). 


\section{Palavras-chave}

Estética. Games. Poiese.

\section{A experiência estética}

Considerações estéticas são mais frequentemente associadas à arte, e quando a questão é levantada em relação aos games, é comum debater se essa mídia pode ser vista como arte ou não. Ainda assim, pensar sobre a experiência estética do jogo de computador pode excluir tais considerações. Baseando-nos em John Dewey (1934), afirmamos que a experiência estética não pode ser reduzida à experiência da arte, e que pode ser a experiência de um jogo de computador, porém nos situamos na questão dos jogos como arte.

Segundo Dewey, qualquer experiência pode se tornar uma experiência estética, pois esse tipo de experiência não é determinada por um objeto definido (uma obra de arte, por exemplo), mas sim pela experiência vivida desse objeto. Em outras palavras, a experiência estética não é definida pelo conjunto de atributos dado por um objeto, mas por um conjunto de critérios que definem a dimensão da experiência.

Por exemplo, pode-se pensar que jogar Trauma, um jogo independente de Krystian Majewski, produziria automaticamente uma experiência estética, considerando os objetivos artísticos do jogo. Tomado na mesma linha do que Myst (CYAN, 1993), este jogo pode se prestar a uma experiência estética em si, dada a originalidade de sua jogabilidade e tratamento visual. Por outro lado, pode ser um jogo muito chato para certos jogadores, que não terão uma experiência estética se o jogo não conseguir tocar suas sensibilidades, e eles preferirão se afastar dele (uma atitude que é contrária a critérios que definem a experiência estética, como veremos mais adiante).

Nesse sentido, nenhum objeto pode predeterminar uma experiência estética, mesmo que apresente certas características que poderiam favorecê-la, porque qualquer experiência pode se tornar uma experiência estética. Dewey (1934) acrescenta que a própria experiência estética é uma experiência do comum, e não uma experiência externa com outras pretensões - associadas à obra de arte, por exemplo. Ao invés disso, esta é uma exibição de características que o próprio jogador seleciona, uma maneira de ampliar algumas qualidades para o prazer. A experiência estética é uma experiência de prazer 
imediato que está sempre em curso, um gozo da experiência real que é, nesse sentido, uma forma de relação com o mundo.

Essa relação é uma experiência total e unificadora, uma combinação de forças que é o oposto da fuga. No caso dos games, ela pode ser concebida como a unificação do jogador ao jogo, a fim de maximizar alguns de seus traços: o jogador amplia algumas características para sua diversão e tem uma experiência estética a partir de sua própria experiência do jogo de computador. Como tal, a experiência estética nada mais é do que seu auto-gozo em um presente sempre em desenvolvimento. Como escreve Dewey, a experiência estética é distinta da experiência em geral pelo fato de não estar vinculada a um dado objeto ou fenômeno: ela é vivida por si mesma e constitui uma experiência da experiência, tornandose seu próprio fim em virtude de uma constante reflexão sobre o seu devir sempre em mudança.

\section{Mundo, regras e affordances}

A relação de um sujeito com o mundo e seus objetos é a questão central de The Ecological Approach to Visual Perception (GIBSON, 1979), um livro que se tornou uma abordagem influente em muitas escolas de psicologia hoje. A abordagem ecológica postula que um sujeito não pode ser pensado independentemente de seu ambiente. Um conceito importante proposto por Gibson, o de affordances, já foi adotado e aplicado a games por muitos pesquisadores, como Dan Pinchbeck (2007), por exemplo. Uma affordance é uma possibilidade de ação oferecida pelo ambiente para um determinado assunto (um animal, nos termos de Gibson), dependendo de suas habilidades e conhecimentos. Assim, uma porta será "abrível" para um animal que tenha o conhecimento necessário para operar uma maçaneta, que seja suficientemente alto para alcançá-la, suficientemente forte para empurrar a porta assim que o mecanismo de trava for operado, e assim em diante. A mesma porta pode oferecer affordances completamente diferentes para outro animal: um castor pode achá-la "mastigável" se for feita de madeira, e um pequeno inseto pode achá-la "contornável" se apresentar uma lacuna grande o suficiente.

Affordances em games são o resultado do encontro de dois tipos de atributos: os objetos e regras internos ao jogo, e as habilidades e conhecimentos do jogador. Por exemplo, um habilidoso jogador de Super Mario Bros. (da Nintendo, 1985) pode dominar diferentes aspectos do salto, mudando sua direção do ar ou limitando propositalmente a altura de seus 
saltos, mas a altura máxima a que Mario pode pular é fixa e inalterável (a não ser que se modifique o código do jogo, claro). 0 jogador não pode exceder o potencial de ação de seu personagem; ele pode ser incapaz de explorá-lo completamente. Para exemplificar este processo, em Super Mario Bros., um jogador habilidoso pode correr a toda velocidade e se abaixar. Ao conservar o momento, Super Mario pode "deslizar" sob blocos e através de lacunas que normalmente só seriam "passáveis" pelo Mario regular (pequeno); esta ação é conhecida pelos jogadores como a técnica de "duck-slide". Este é um affordance do personagem que deve ser executado através de uma affordance do jogador que requer um certo grau de habilidade.

Assim, é mais adequado pensar os games a partir de termos ecológicos, pois um dado jogo sempre trabalha com um jogador implícito, modelo ou mesmo com um público implícito em mente¹. Em Super Mario Bros., a técnica de "duck-slide" nunca é necessária para que um jogador complete um nível do jogo. Como mostrado na figura 1, o jogador pode usálo para deslizar sob os tijolos, bloqueando o caminho no Mundo 1-2, se ele estiver em seu aspecto de Super Mario, mas sem essa técnica avançada, ele pode simplesmente quebrar os tijolos na frente do espaço e passar por cima. 0 jogo, portanto, não força o jogador a dominar essa técnica, ainda que pudesse fazê-lo com facilidade. Se a imagem mais à direita abaixo fosse realmente implementada em Super Mario Bros., então a ação pretendida seria diferente, pois o jogo exigiria que os jogadores dominassem essa técnica (já que os blocos sólidos não podem ser quebrados por Super Mario).

\footnotetext{
1 O Leitor Modelo, de Umberto Eco (1986), para citar apenas uma proposição teórica, foi adaptado e questionado anteriormente para o contexto dos game studies por vários autores. Escolhemos ignorar muitas distinções e nuances que poderiam ser discutidas para que o artigo possa manter-se em foco
} 
Figura 1 - Super Mario
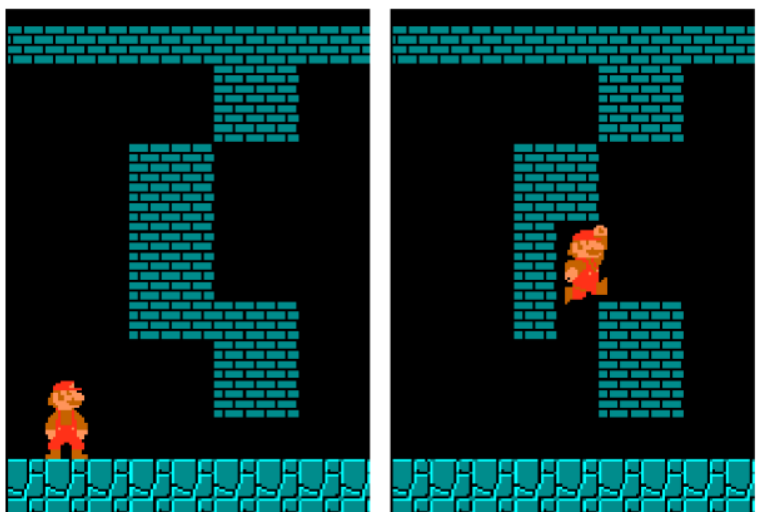
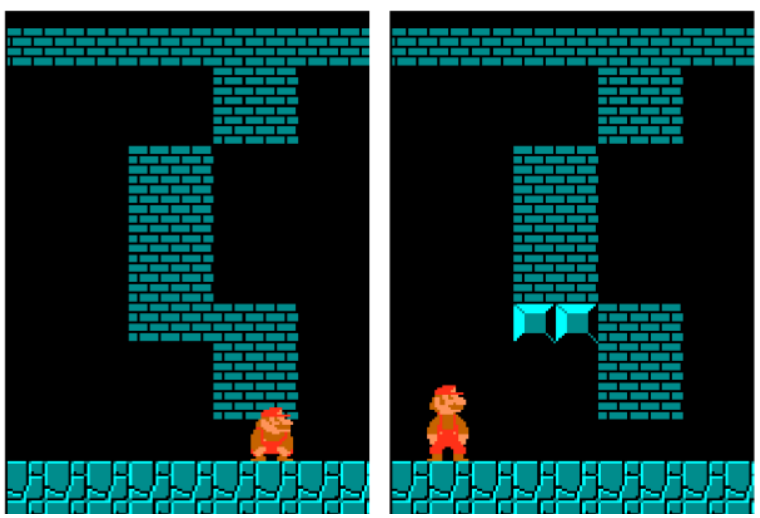

Fonte: Autor.

Legenda: Mais à esquerda: Super Mario na frente do problema: um pequeno espaço. Centroesquerda: A solução óbvia e natural: quebrar os blocos para passar. Centro-direita: Super Mario executando a técnica duck-slide para deslizar por baixo dos blocos. Mais à direita: Um caso hipotético no qual a técnica de duck-slide seria obrigatória.

Podemos dizer que o que quer que o jogo exija especificamente, e que não dependa da liberdade e do livre arbítrio do jogador em, e de si mesmo², se apoia mais fortemente no funcional do que no estético; a experiência estética do jogo de computador é uma experiência de jogo livre alcançada através da atualização de affordances - nem "free-play", sem qualquer consideração das affordances do jogo, nem a simples execução de ações requeridas sem criatividade pessoal (caso em que poderíamos afirmar, de acordo com Seth Giddings e Helen Kennedy (2008), que o jogo dominou o jogador). No caso do "duck-slide", há uma experiência da experiência, uma vez que essa atualização, essa abordagem de um problema de jogo, é um caso de composição (que discutiremos mais adiante) e é totalmente "desnecessária". A superação do problema é necessária, mas o jogador é livre para desenvolver sua própria abordagem criativa para fazê-lo. Assim, uma investigação sobre as noções de imaginação e criatividade parece necessária.

\section{Imaginação}

A imaginação de um jogador é o que permite um retorno reflexivo na experiência do

\footnotetext{
2 “[E]m, e de si mesmo” é importante aqui; ao usá-lo, queremos impedir tais situações em que o jogador tenha que executar algumas ações obrigatórias que ele não quer fazer para que ele "passe para a parte boa". É verdade que ele está, em um nível mais global, jogando o jogo por seu próprio livre-arbítrio; mas dentro do escopo dessa atividade voluntária, há algumas coisas que precisam ser feitas, quer o jogador queira fazê-las ou não. Essas situações não são vivenciadas pelo jogador "em si e por si", mas são instrumentalizadas como parte de um objetivo de longo prazo: elas carecem de auto-apreciação e do foco no desdobramento presente que são fundamentais para a experiência estética de Dewey.
} 
game para que novas formas de fazer as coisas possam ser realizadas. Para Dewey, a imaginação é uma maneira de ligar o passado e o futuro para que o significado possa ser produzido; poderíamos dizer que a imaginação permite a produção de significado através dos conhecimentos e experiências passados de um jogador, a experiência futura do jogo e aqueles conhecimentos e experiências que ela molda no presente em curso. Na esteira do trabalho de Wolfgang Iser e Hans R. Jauss na teoria da recepção (ISER 1978; JAUSS, 1983), Dominic Arsenault e Bernard Perron (2009) mostraram como o horizonte de expectativa do jogador é moldado pelos elementos discursivos limítrofes ao redor do jogo que Gérard Genette (2009) descreveu como formador do paratexto. O paratexto tem como objetivo fazer com que essas expectativas correspondam ao leque de possibilidades que o jogo oferecerá, permitindo ao jogador se engajar no processo de testar, descobrir e mapear mentalmente essas possibilidades. 0 paratexto realmente é, para assumir o termo de Genette, um limiar, ligando as experiências passadas e o conhecimento para moldar as expectativas do futuro. Ele serve uma função importante como forma de canalizar a imaginação.

Como os games constantemente apresentam novas situações, o ato de jogar está sempre focado na tarefa presente, ainda que esta tarefa seja parte de uma busca e rede maiores de relacionamentos entre objetos, processos computacionais e sistemas de jogabilidade que continuam se desdobrando. Ter acesso a uma nova unidade em StarCraft (BLIZZARD, 1998) que é mais forte e blindada tem um significado imediato, no momento presente (algo como um "power-up"), mas também um segundo significado: a antecipação de futuros inimigos ou situações que irão desafiar essa força recém descoberta. 0 mesmo ocorre em jogos como Resident Evil (CAPCOM, 1996), onde os recursos são escassos; quando o jogador recebe muitas ervas para a saúde (heatlh herbs) e munições, ele sabe que esse "presente" é, na verdade, parte de uma sequência maior: sem dúvida, uma grande luta se aproxima. Quando considerado como parte de uma experiência estética do jogo, o jogador está se apropriando de todos os elementos do jogo para otimizar seu presente sempre em renovação, e imaginando as melhores formas de lidar com os obstáculos futuros. Nesse caso, a imaginação está unificando os elementos heterogêneos do jogo em um todo idealizado, do qual uma experiência estética é extraída. A imaginação, portanto, permite a antecipação de outras possibilidades ainda não concretizadas, graças à criação. 


\section{A criatividade do jogador como forma de união com o jogo}

Propomos como hipótese que a imaginação de Dewey é de fato a poiesis, apresentada pelos filósofos pré-socráticos e retomada por Heidegger (1987), entre outros filósofos contemporâneos. Poiesis é então considerado "um modo de revelação ( $a$-letheia) do Ser" (Ferrari Di Pippo, 2000, p. 3), uma ação de construção de mundo, de manifestar o que antes era inexistente. A poiesis é responsável pela abertura do Ser e é a fonte da criação e da diferença no mundo. Essa criação pode ser imaginada em dois níveis, que evocamos anteriormente em nossa discussão sobre affordances: o primeiro diz respeito ao jogador, sua atitude, seu conhecimento e experiências anteriores e sua vontade (o que o jogador consegue alcançar), enquanto o segundo diz respeito ao objeto "game" e às possibilidades de experiências estéticas que estão incluídas em sua estrutura: em outras palavras, suas potencialidades e qualidades (o que o jogo permite). Estamos separando-os para identificálos e discuti-los, mas, na prática, eles trabalham juntos: é por isso que o conceito de affordances é tão bem adaptado ao jogo de computador. A poiesis capacitada pelo esforço da imaginação é que liga e mantém a experiência do objeto como uma entidade singular, mas sempre nova e em formação.

Nesse sentido, nossa definição de estética é herdada da teoria da resposta estética de Wolfgang Iser (ISER, 1978), que é uma escolha natural, dado o trabalho de Iser sobre a interpretação como o "mapeamento produtivo de territórios sempre novos" (ISER, 2000, p. 158) proveniente do jogo e caracterizada pela criatividade pessoal e pela emergência. Assim, a experiência estética do game pode ser considerada como a apropriação pessoal dos padrões e mecânicas do jogo pelo jogador, estratégias singulares e modos de jogo que mostram uma subjetividade diretamente fora da objetividade do algoritmo. No game existe a criação de uma experiência que é por definição nova e imaginativa para o jogador, ou então o jogo propriamente dito não existe: deve haver uma indeterminação de resultados para o jogador, ou seja, a atualização de uma parte do jogo. virtual por meio de sua imaginação.

0 jogador atualiza o que ainda não aconteceu, graças à maximização de uma ideia incluída nas regras que a imaginação explora. A experiência estética no jogo é avaliada a partir do processo pragmático do jogador como o criador de sua própria experiência de jogo. 0 jogador criativo tem a possibilidade de transformar sua experiência de jogo de computador em uma exploração estética, onde ele é afetado pelo jogo e o afeta a partir de 
critérios que se enquadram no reino da Beleza (ritmo, equilíbrio, graça, harmonia, etc.). Estudos sobre a beleza remontam aos primeiros escritos da antiguidade grega, e Huizinga (2000) até afirma que os mesmos termos são usados para descrever a arte e o jogo, pois, considerando todas as coisas, ambos nos afetam igualmente por meio do encanto.

A noção de Beleza pode ser desenvolvida considerando-a como uma relação entre forças onde há ritmo, equilíbrio, graça e harmonia que permitem pensar a experiência estética. Baseando-nos em Spinoza, podemos dizer que esta beleza não é apenas uma relação entre forças, mas também um aumento na agência graças a uma união de forças em "composição" (em oposição à "decomposição"). Na ordem de composição, há um equilíbrio de forças em direção à unidade; na decomposição, pelo contrário, há desequilíbrio e impossibilidade de se ter uma experiência estética ${ }^{3}$. Por exemplo, a presença de uma estratégia dominante, "uma que supera todas as outras por ser a melhor escolha em qualquer circunstância" (ROLLINGS; ADAMS, 2003, p. 244), é um exemplo de decomposição: se algumas estratégias são clara e invariavelmente melhores do que qualquer outra, elas tornam qualquer outra opção discutível. Assim, a agência de qualquer jogador é potencialmente reduzida - a menos que esse jogador não esteja tentando jogar "para ganhar", para maximizar sua eficiência ou chances de ganhar. Há composição quando os oponentes lutam de forma equilibrada, em união de ritmo, graça e harmonia.

Assim como o surfista se une à onda em vez de lutar contra ela (para pegar o exemplo de Deleuze), o jogador une suas forças às do jogo e às dos outros jogadores (no caso de jogos multiplayer) para aumentar sua agência e maximizar as possibilidades incluídas na estrutura do jogo. Na experiência estética, há composição do jogador para o jogo e os outros jogadores. Como Dewey, postulamos que a experiência estética é uma experiência de unidade: é ser "como que um só" com o jogo e os outros jogadores, unindo forças para aumentá-las e maximizar a experiência - que então se torna uma experiência da experiência. Poderíamos levar a ideia adiante e falar de um momento de graça para descrever o momento em que o jogador maximiza suas forças junto às forças do jogo e dos outros jogadores, quando o que era até então virtual é atualizado para que o jogador possa experimentá-lo - tornando-se um experiência estética.

\footnotetext{
${ }^{3}$ Quando examinada no contexto de jogos multiplayer, essa noção se vincula a questões de fair-play e griefing: o griefer pode ser o jogador que rejeita qualquer forma de conformismo com as regras ou objetivos do jogo e não se preocupa com o equilíbrio do jogo. Enquanto a maioria dos jogadores competitivos parará de jogar um jogo que é desequilibrado, os griefers continuarão jogando enquanto puderem colher os desequilíbrios a seu favor. Essas questões, no entanto, certamente se beneficiariam de estudos mais aprofundados.
} 


\section{0 momento de graça da experiência estética}

Este pode parecer um problema trivial, mas existem questões que precisam ser levantadas: o momento da graça é o momento em que o jogador executa as ações ou o momento em que ele entende como os elementos podem se conectar? Em muitos jogos de ação, esses dois momentos podem ocorrer quase que em simultaneidade. No entanto, não é incomum para jogadores de jogos de estratégia pensar em seus próximos movimentos possíveis ou de estratégias alternativas quando eles não estão jogando o jogo, e estão em ambientes mundanos.

Isso atesta o papel da imaginação na definição de experiência estética de Dewey, como uma função que liga o passado e o futuro; e também requer que identifiquemos dois pontos particulares na linha do tempo da experiência estética: o momento da graça, onde as estratégias e virtualidades são atualizadas e se solidificam em um equilíbrio ideal; e em um momento fecundo, seguindo Gotthold Lessing (1766). Originalmente cunhado no contexto da pintura e escultura, o momento fecundo é o momento de máximo impacto dramático e representacional. Estamos adaptando o conceito de Lessing, uma vez que ele foi usado como uma maneira de identificar esse momento como parte de uma narrativa da qual o objeto em particular era uma manifestação. Nosso uso, no entanto, não é focado no objeto em si, mas na experiência de um determinado jogador. Isso ocorre porque a interatividade inerente ao jogo envolve uma medida de variação entre o desdobramento temporal das jogadas individuais de um dado jogo. Mesmo com essa importante diferença, o momento fecundo é um conceito importante e útil. Não é, como um retrato ou uma natureza morta, uma imagem a ser tomada isoladamente, mas é uma parte retirada de um todo (uma determinada cena ou evento); ele conta com a imaginação do espectador para reconstruir o restante da cena (normalmente, a ação que está prestes a ocorrer).

O momento fecundo, como trampolim para a imaginação e como parte de um todo, desempenha um papel fundamental na experiência estética de Dewey. Aplicado ao contexto do jogo de computador, o momento fecundo pode ser comparado ao momento «Eurêka!»: aquele momento em que as coisas "clicam" juntas, quando possibilidades conhecidas são visualizadas de uma maneira nova, ou quando uma nova estratégia é criada. 0 momento da graça então se segue quando esse novo plano é colocado à prova e revela uma medida de beleza anteriormente insuspeitada. 
Assim como a experiência estética, o momento da graça não pode ser definido em termos transcendentais para todos os jogadores: é único e imanente ao jogador. Não é definido por uma soma de traços predeterminados pelo objeto, mas por critérios que definem a dimensão da experiência do jogador. Este momento pode ser, no caso de um jogo multiplayer, quando todos os jogadores unem suas forças ao mesmo tempo, em harmonia, em rara unidade. Por exemplo, os jogadores de Mount and Musket: Battalion (um mod de Mount \& Blade: Warband) podem ter vivido um momento de graça quando travaram uma épica batalha de 125 jogadores, com cada jogador unido ao jogo e aos outros. Embora os franceses tenham perdido, a união de jogadores, sua sincronicidade tanto com eles quanto com seus adversários, e suas ações coordenadas são elementos que podem ser considerados parte da experiência estética. Nesse sentido, a vitória ou a derrota não é um critério determinado da experiência estética, já que esse tipo de experiência não responde a nenhum outro objetivo senão a si mesmo. A experiência técnica ainda está acontecendo, já que os jogadores precisam manipular adequadamente seus objetos e interface no jogo; mas essa experiência é duplicada por uma experiência estética que tem predominância sobre as considerações funcionais de "jogar o jogo" no sentido mais básico (que está mais perto de "ser jogado pelo jogo"). Essa experiência em particular é vivida em si e por si só, em virtude do jogo: os jogadores do Mount and Musket veem sua colocação na linha de frente e a execução harmoniosa de suas ações como mais importante do que vencer ou mesmo lutar. A batalha deve, em primeiro lugar, ser «bela».

Embora o objeto não determine inteiramente a experiência que pode ser obtida nem o jogador possa fazer o que ele quer com qualquer jogo, existe uma correlação entre, de um lado, expertise e domínio sobre um jogo, tanto para conhecimento quanto para habilidade. (através da exploração das affordances por parte do jogador) e, por outro lado, a realização de uma experiência estética plenamente desenvolvida, isto é, a atualização da estética ideal (idealis) do jogo (através dos atributos do jogo que moldam as affordances). De fato, a imaginação do jogador depende de seus conhecimentos e habilidades adquiridos, e quanto mais ele puder acessar, mais forte ele será, uma vez que o jogador terá mais possibilidades de ação. Se o jogador não conhece o jogo ou é incapaz de executar algumas ações, sua experiência estética será limitada àquelas possibilidades que ele pode realmente usar. 


\section{Conclusão}

Em outras palavras, a forma do poder potencial de criação que reside na relação entre o jogador e o objeto de jogo (a experiência estética) depende do conhecimento, das habilidades e experiências técnicas prévias para o pleno florescimento das possibilidades e potencialidades de um game. De acordo com o paradigma foucaultiano de conhecimento e poder, quanto mais um jogador conhece um jogo, mais ele pode se unir e maximizar suas forças ao jogo para transformar sua experiência em uma experiência estética única em virtude do processo de apropriação criativa. É nesse sentido que há criação, poiesis: uma nova organização de forças em virtude da imaginação do jogador, trabalhando em seu relacionamento com o jogo, seja ele compatível com o que os projetistas do jogo ou seus outros jogadores esperariam ou não. Poderíamos, assim, propor uma definição das possíveis experiências estéticas de acordo com a que se busca ou não os objetivos declarados do jogo. No primeiro caso, a experiência estética do jogador inscreve-se no ludus e, no segundo, é bastante tributária do paidea (CAILLOIS, 1990).

Essa abertura para uma categorização de experiências estéticas exigiria uma investigação mais detalhada, mas por enquanto podemos averiguar a singularidade da experiência estética do jogo de computador. Independentemente de o jogador jogar como é esperado ou não, a partir de sua própria perspectiva, ele atualiza novas possibilidades e inventa para si uma nova experiência; essa é a razão pela qual afirmamos anteriormente que a experiência estética é avaliada a partir do processo pragmático do jogador como o criador de sua própria experiência de jogo. Como tal, a experiência estética torna-se uma forma de testar a si mesmo e não pode ser pensada fora da experiência ética: que tipo de experiência o jogador terá interesse em ter (tanto para si como para os outros no caso de jogos multiplayer), e o que ele fará de sua liberdade e criatividade? Não é de surpreender que, desde a Antiguidade grega, muitos filósofos tenham abordado o jogo associando-o a considerações estéticas, mas também éticas.

\section{Referências}

ARSENAULT, Dominic; PERRON, Bernard. In the frame of the magic cycle: The circle(s) of gameplay. In: WOLF, M.; PERRON, B.. The video game theory reader 2. New York: Routledge, 2009. p. 109-131 
CAILLOIS, Roger. Os jogos e os homens: a máscara e a vertigem. Lisboa: edições Cotovia, 1990.

DELEUZE, Gilles. Espinoza: filosofia prática. São Paulo: Escuta, 2002.

DEWEY, John. Art as experience. New York: Berkley Publishing Group, 1934.

ECO, Umberto. Lector in Fabula: a cooperação interpretativa nos textos narrativos. São Paulo: Perspectiva, 1986

FERRARI DI PIPPO, Alexander. The Concept of Poiesis in Heidegger's An Introduction to Metaphysics. Iwm Junior Visiting Fellows Conferences, Viena, v. 9, n. 3, 2000.

GENETTE, Gérard. Paratextos Editoriais. Cotia: Ateliê Editorial, 2009.

GIBSON, James. The ecological approach to visual perception. Boston: Houghton Mifflins, 1979.

GIDDINGS, Seth; KENNEDY, Helen. "Little Jesuses and Fuck-off Robots: On Aesthetics, Cybernetics, and Not Being Very Good at Lego Star Wars". In: SWALWELL, M. E WILSON, J. M. (eds.).The Pleasures of Computer Games: essays on cultural history, theory and aesthetics. Jefferson: McFarland, 2008.

HEIDEGGER, Martin. Introdução à metafísica. São Paulo: Inst. Piaget, 1987.

HUIZINGA, Johan. Homo Ludens. São Paulo: Perspectiva, 2000.

ISER, Wolfgang. The Range of Interpretation. New York: Columbia University Press, 2000

ISER, Wolfgang. The Act of Reading: A Theory of Aesthetic Response. Baltimore: Johns Hopkins University Press, 1978.

JAUSS, Hans Robert. Towards an Aesthetic of Reception. Minneapolis: University of Minnesota Press, 1982.

LESSING, Gotthold Ephraim. Laocoon: or, The limits of Poetry and Painting. London: Ridgeway, 1836.

PINCHBECK, Daniel. Counting barrels in Quake 4: affordances and homodiegetic structures in FPS worlds. In: DIGRA, 2007, Tóquio. Proceedings.... . Tóquio: Universidade de Tóquio, 2007. p. 8 - 14.

ROLLINGS, Andrew; ERNEST, Adams. Andrew Rollings and Ernest Adams on Game Design. Berkeley: New Riders, 2003.

SPINOZA, Baruch. L'éthique. Paris : Gallimard, 1993. 


\title{
Poiesis and Imagination in the aesthetic Experience: The Moment of Grace in Computer Game Play
}

\begin{abstract}
What is the nature of a video game player's experience? Experiencing a computer game is a functional experience, adapted to its function as a computer game. This function is defined by the sum of the properties that produce the meaning of a computer game experience, distinct from other experiences of human existence: the player attributes this particular meaning to his experience rather than another. The properties of this experience can be divided according to its many dimensions, such as technique (têkhné), ethics (ethos), aesthetics (aisthêtikos), etc., and are responsible for the richness and complexity of the human experience. These dimensions can not be visualized separately from their combined effects and they function as an inseparable whole that defines the meaning of life. However, for the needs of our demonstration, we will focus on a study of the aesthetic dimension of the game player experience to show how it unfolds, regardless of the diversity of the games played, whether they are Super Mario Bros. (Nintendo), Mount and Musket: Battalion (independent) or Trauma (Krystian Majewski).
\end{abstract}

\section{Keywords}

Aesthetics. Games. Poiesis.

Recebido em 00/00/0000

Aceito em 00/00/0000 